Article

\title{
Agricultural Structure Adjustment and Rural Poverty Alleviation in the Agro-Pastoral Transition Zone of Northern China: A Case Study of Yulin City
}

\author{
Yongsheng Wang ${ }^{1, *}$, Yan Chen ${ }^{2, *}$ and Zhengjia Liu ${ }^{1}$ (D) \\ 1 Institute of Geographic Sciences and Natural Resources Research, Chinese Academy of Sciences, \\ Beijing 100101, China; liuzj@igsnrr.ac.cn \\ 2 School of Public Administration and Law, Northeast Agricultural University, Harbin 150030, China \\ * Correspondence: wangys@igsnrr.ac.cn (Y.W.); wangyueone@mail.dlut.edu.cn (Y.C.)
}

Received: 23 April 2020; Accepted: 18 May 2020; Published: 20 May 2020

\begin{abstract}
Poverty restricts rural sustainable development and urban-rural integration. Agricultural development is an engine of rural economic development and poverty elimination. Agricultural structure adjustment and rural poverty alleviation in Yulin City from the agro-pastoral transition zone of Northern China were studied using statistical data. Our results showed that the rural poverty ratio in Yulin was $7.70 \%$ in 2017, with clearly higher trends in southeast regions and lower trends in northeast regions. Northern Yulin had a lower proportion of primary industry to gross domestic production and ratio of agriculture to animal husbandry than southern Yulin. The agricultural structure variability index and agricultural specialization index have changed little, while the actual growth rate of the rural per capita net income has dramatically declined in the last decade. The rural poverty ratio was positively correlated with proportion of primary industry and ratio of agriculture to animal husbandry. These results suggest that a reduced proportion of primary industry and animal husbandry development will promote rural poverty alleviation and future rural revitalization.
\end{abstract}

Keywords: rural poverty; agricultural structure adjustment; agricultural specialization; sustainable development

\section{Introduction}

The rural system has a certain structure and function consisting of several interconnected and interactive elements [1]. Accelerated urban and rural element flow has resulted in a significantly changed structure of the rural areal system, industry, and society [2,3]. The rural areal system function has developed from a single function to one of diversification, with features of "production-life-ecology-culture" [4,5]. Comparatively, China's dual-track structure of urban-rural development emphasizes the crucial roles of the rural system in maintaining social stability and ensuring farmers' livelihood, rather than in improving agricultural functions. The urban and industry priority development strategies have promoted the flow of labor, land, and capital from rural to urban areas. Regional discrepancies, rural poverty, and rural land-use issues are major potential factors influencing the building of a new countryside in China [6]. Rural revitalization should be emphasized during the process of rapid urbanization [7]. Identifying deficient elements, improving the development structure, and elevating rural functions needs to be urgently realized for rural transformation and development.

Rural sustainable development faces severe "rural disease", characterized by the high-speed non-agricultural transformation of agricultural production factors, over-fast aging and weakening of rural subjects, increasing hollowing and abandoning of rural construction land, severe pollution of rural 
land and the water environment, and deep pauperization of rural poverty-stricken areas [1]. Worsened rural instability and vulnerability are the weak points of urban and rural equality development [8]. Rural decline has become a global issue of rapid urbanization, leading to severely poor nations and deepening rural poverty. Poverty has been considered to be related to a shortage of materials and lack of opportunities, as well as access to social services [9]. Poverty has many dimensions, including not only income poverty, but also education, public health, drinking water and sanitation facilities. Poverty reduction and sustainable development are inseparable. Poverty reduction is the priority direction for global development and is the only solution to achieve the Millennium Development Goals and the 2030 Sustainable Development Goals [10]. China was once the developing country with the largest rural poor population in the world. Most of China's poor populations are widely distributed in fragile environments with backward infrastructure and frequent disasters. It is more difficult to lift the remaining poor population out of poverty induced by disease, disability, and natural disasters [11]. The Chinese government has carried out the targeted poverty alleviation strategy to eliminate rural decline and poverty. The 19th National Congress of the Communist Party of China proposed a rural revitalization strategy to solve inadequate rural development. Agricultural and rural areas have become the priority development regions for the future 30 years. However, the endowments of people, land, industry, capital, and institution in poor areas make meeting the requirements of rural revitalization difficult. The migration of young people to cities leaves elderly, sick, and disabled people in rural areas [12]. Serious land issues have emerged, such as farmland abandonment and pollution, landless peasants, and hollowing villages [13]. Rural collective economics are still weak, with a scattered agricultural industry

Poverty alleviation is a global challenge. Many theories and strategies have been developed to improve the rural poverty situation [14]. Agriculture is the major economic activity in rural area and the foundation for the livelihood maintenance of rural households [15]. Rural people use land, water, and biotic resources as dominant elements for agricultural production [16]. Agricultural productivity plays a determinant role in poor countries' development process [17]. Agriculture growth has positive impacts on rural poverty reduction, from the promotion of the farm economy and rural economy to national economy [18]. Valdés and Foster [19] pointed out that agriculture's principal role in poverty reduction is greater than its simple share of national domestic production. Therefore, identifying the agricultural structure evolution trend and releasing an adjustment strategy is necessary for agricultural production and rural economic development in poor areas.

Structural transformation in the agriculture sector aims to increase the productive capacity or degree of flexibility of the economy through the adjustment of planting, forestry, animal husbandry and fishery. Agricultural structure adjustment can achieve the supply-demand balance by changing production structure, organization structure and development structure based on resources and environmental capacities and market demand [20]. A strong relationship was found between structural transformation and economic development. Herrendorf et al. [21] suggested that structural transformation is a prerequisite of sustainable economic growth and poverty alleviation. Agricultural structure adjustment policies are important ways to increase farmers' income and favor the poor [22]. Optimizing the structure of the rural agricultural industry and creating an agricultural economy with a stable and higher income is essential for both environmental protection and social development in degraded areas [23]. China has achieved remarkable success in alleviating rural poverty in the last seven decades. Innovative poverty alleviation policies and measures have significantly promoted rural industries and education development, infrastructure construction, and disease treatment. Innovative agricultural structure adjustment strategies and excellent practices need to be shared globally and help other countries overcome poverty.

Natural resources and environmental quality are considered to be welfare determinants [24]. Environmental degradation contributes to rural poverty by decreasing land productivity and worsening the poor's health [25]. The agro-pastoral transition zone of Northern China, located in an arid/semi-arid area, is a key area of ecologically friendly construction and poverty alleviation in China. Conflicts 
between agricultural production and animal husbandry development, rural livelihood improvement, and ecological environment protection are deepening under climate change and urbanization [26]. Over-reclaiming, over-grazing, and over-cutting have caused land degradation, frequent natural disasters, and rural poverty [27]. In 2017, China's Ministry of Agriculture proposed the Work Plan for Promoting Agricultural Structure Adjustment in Northern Agro-pastoral Transition Zone to optimize the agricultural structure and increase local farmers' income. There is an urgent need to point out the current agricultural structure, limiting factors, and inefficient development areas.

Yulin has been famous for the successful restoration of Mu Us Sandy Land in the last 40 years. Massive ecological construction projects, such as the Grain-for-Green program, grazing prohibition, and Three-North Shelterbelt Forest Program, significantly increased normalized difference vegetation index with the rate of 0.0076 year $^{-1}$. Ecological quality of Yulin has been improved continuously during the period 1990-2010 [28]. However, Yulin has a large proportion of its population that is dependent on the farming and animal husbandry, mainly distributed in the south areas. Agricultural development has been neglected since scale natural resource exploitation from the 1980s [29]. We hypothesized that a higher poverty ratio was found in the regions with a higher proportion of agricultural economy. In addition, we also hypothesized that improving agricultural economic benefit measures, such as agricultural specialization and structure adjustment, could help reduce rural poverty. Our results will provide a theoretical foundation for regional agricultural and rural sustainable development.

\section{Materials and Methods}

\subsection{Site Description}

Yulin City located in Shaanxi Province of Northwest China. Northern wind-sand-grass shoal and southern loess hilly-gully regions account for $36.7 \%$ and $51.8 \%$ of the total area of Yulin, respectively (Figure 1). The temperate arid/semi-arid continental monsoon climate dominates this region, with a mean temperature of $8.4^{\circ} \mathrm{C}$, a mean precipitation of $398.3 \mathrm{~mm}$, and cumulative sunshine of 2594-2914 $h$. The southern region has higher mean temperature and annual precipitation than the northern region while the cumulative sunshine of southern region is lower than that of the northern region. Yulin is an important resource-based city in China in terms of coal, oil, natural gas, and rock salt. Secondary and tertiary industries play the dominant role in Yulin economic development. All of the mineral resources are mainly distributed in the six western to northeastern counties, including Dingbian, Jingbian, Hengshan, Yuyang, Shenmu, and Fugu (Figure 1). Yulin has been recognized as the key area of national targeted poverty alleviation, with eight national-level poverty-stricken counties, including Jia, Mizhi, Zizhou, Suide, Wubu, and Qingjian counties in the southeast, and Dingbian and Hengshan in the northwest.

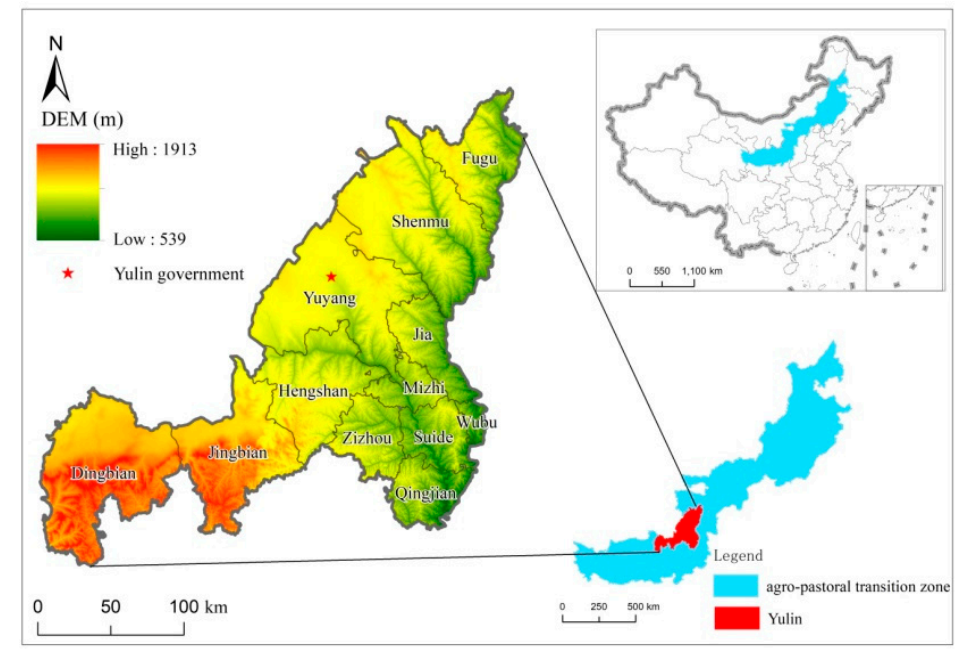

Figure 1. Administrative division and geographical location of Yulin City. 


\subsection{Data Sources}

The data resource at county level used for this study is government statistical data. The rural poverty ratio from 2014 to 2017 was collected from the Yulin Poverty Alleviation Offices. The industry production value, crop planting areas, rural per capita net income, and rural consumer price index data during the period 2008-2017 were collected from the Yulin Statistical Yearbook (http://data.cnki.net/ yearbook/Single/N2019010034). However, the statistical data from the yearbook did not include 2013.

\subsection{Methodology}

Yulin is a typical agro-pastoral transition area. Agricultural planting and livestock breeding is the traditional agricultural industry, giving farmers a chance to feed their families. We chose the proportion of primary industry to gross domestic production and the ratio of agriculture to animal husbandry to evaluate the agricultural economic development status. The location quotient, agricultural structural variability index and agricultural specialization index was generally used to analysis agricultural structure adjustment and transformation [20]. However, the crop planting scale will be magnified due to a lower proportion of primary industry in county-level location quotient analysis. Less than $15 \%$ of proportion of primary industry to gross domestic production was found in southeast counties of Yulin. Therefore, only agricultural structural variability index and agricultural specialization index were chosen in our study.

\subsubsection{Agricultural Structural Variability Index}

Agricultural structural variability index was used to present the agricultural planting. Wheat, rice, maize, and potatoes were used as grain crops, and soybean, peanut, hemp, vegetables, melon, and fruit were used as commercial crops, to calculate the agricultural structural variability index using Expression (1)

$$
\text { ASVI }=\operatorname{arcos}\left\{\frac{\sum_{i} S_{i}(t) \times S_{i}(t-n)}{\sqrt{\left(\sum_{i} S_{i}(t)^{2}\right) \times\left(\sum_{i} S_{i}(t-n)^{2}\right)}}\right\}
$$

where ASVI represents the structural variability index. $\mathrm{t}$ and $\mathrm{t}-\mathrm{n}$ represents the base year and last year. $S_{i}(t)$ and $S_{i}(t-n)$ indicate the proportion of crop $i$ planting areas to the total planting areas in year $t$ and year $(t-n)$, respectively. A larger value of ASVI shows a more significant difference in the agricultural planting structure.

\subsubsection{Specialization Index}

Agricultural specialization index was used to calculate the crop planting specialization degrees using Expression (2)

$$
\mathrm{ASI}=\left\{1+\frac{\sum_{i} S_{i} \times \ln S_{i}}{\ln n}\right\} \times 100 \%
$$

where $S_{i}$ indicates the planting area of crop $i$ and $n$ indicates the number of crop varieties. A larger value of ASI shows a higher level of crop planting specialization.

\subsubsection{Actual Growth Rate of Rural Per Capita Net Income}

The nominal growth rate is used to express the absolute change of rural per capita net income using Expression (3). The actual growth rate of rural per capita net income reflects the actual income growth degree after removing the price factor. Actual growth rate is calculated by Expression (4) using the nominal growth rate and rural consumer price index. Rural income in 2008 was set as the standard value of 100

$$
X_{i}=\frac{\left(Y_{i}-Y_{i-1}\right)}{Z_{i}}
$$




$$
\mathrm{AGR}_{\mathrm{i}}=\frac{\left(1+\mathrm{X}_{\mathrm{i}}\right)}{\mathrm{Z}_{\mathrm{i}}-1}
$$

where $Y_{i}$ and $Z_{i}$ represent the rural per capita net income and rural consumer price index in the year $i$ respectively.

\subsubsection{Statistical Analysis}

Linear regression analyses were used to examine the relationships between poverty ratio and the proportion of primary industry to gross domestic production, ratio of agriculture to animal husbandry, agricultural structural variability index and agricultural specialization index in 2017 at county-level. Poverty ratio was set as the dependent variable, and proportion of primary industry to gross domestic production, ratio of agriculture to animal husbandry, agricultural structural variability index and agricultural specialization index were set as the independent variables. All statistical analyses were conducted using the SPSS software package (version 16.0), and significant differences were set with $p$ values $<0.05$ unless otherwise stated. Figures were drawn using the ArcGIS (version 10.3) and Sigmaplot software package (version 10.0).

\section{Results}

\subsection{Rural Poverty Ratio}

In 2017, Yulin had an average rural poverty ratio of $7.70 \%$ with clearly higher trends in the southeast and lower trends in the northeast. In the six west to northeast counties, the poverty ratio ranged from $1.19 \%$ to $5.98 \%$, with the lowest and highest values in Yuyang and Dingbian, respectively. The southeast had a higher poverty ratio, which ranged from $11.59 \%$ to $18.12 \%$, with an average of $14.54 \%$. Qingjian County had the highest poverty ratio of $18.12 \%$ (Figure 2).

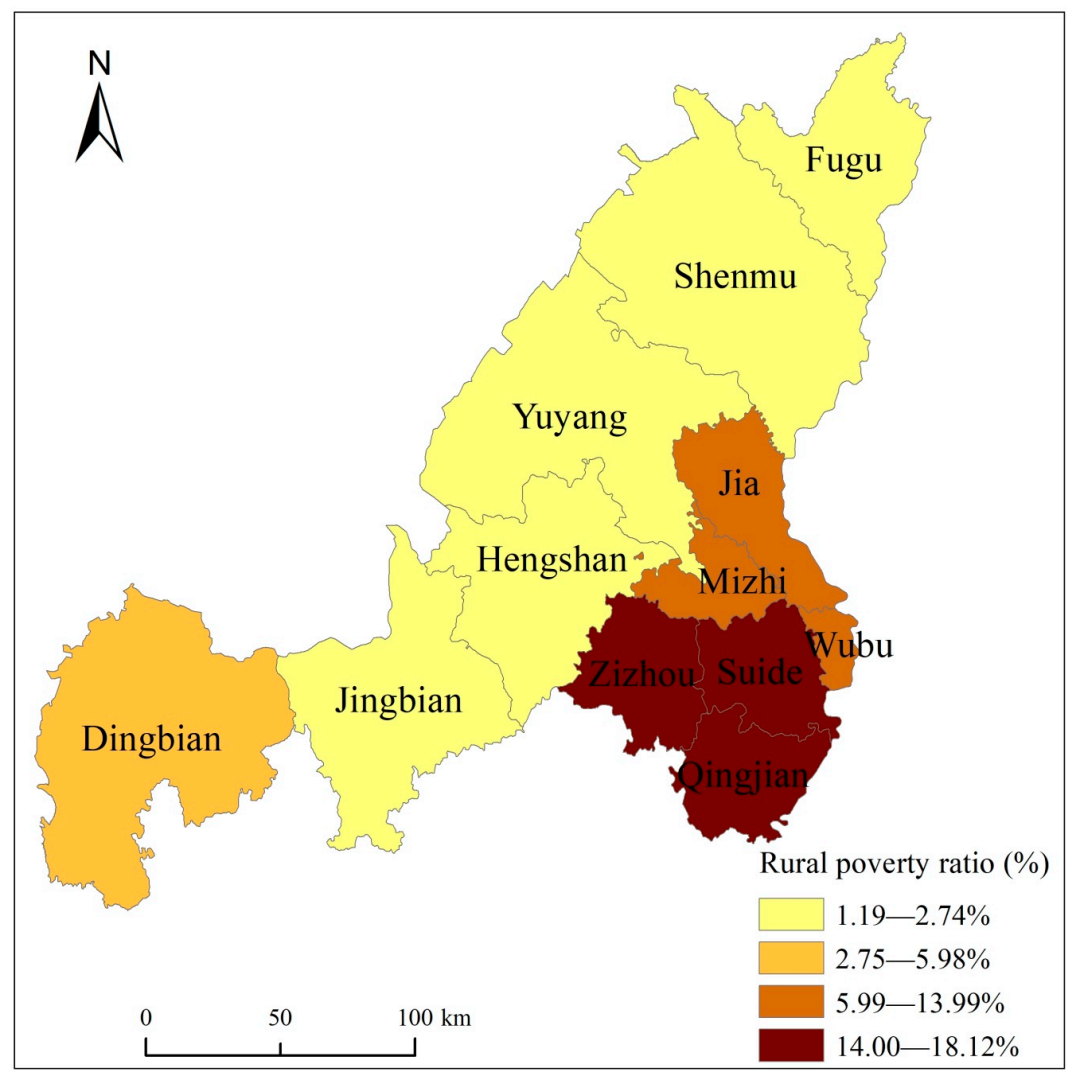

Figure 2. Rural poverty spatial distribution of Yulin City in 2017. 


\subsection{Primary Industry Development}

\subsubsection{Proportion of Primary Industry}

Proportion of primary industry to gross domestic production decreased from $9.40 \%$ in 2008 to $7.85 \%$ in 2012, and then increased to $10.18 \%$ in 2016. Jia and Qingjian had the highest proportion of primary industry. The proportion of primary industry values in Zizhou, Suide, Wubu, and Mizhi counties were above 20\%. Yuyang, Dingbian, and Jingbian had approximately the same proportion of primary industry as the average level of Yulin, while Fugu and Shenmu had a lower proportion of primary industry than the average level of Yulin (Figure 3a).

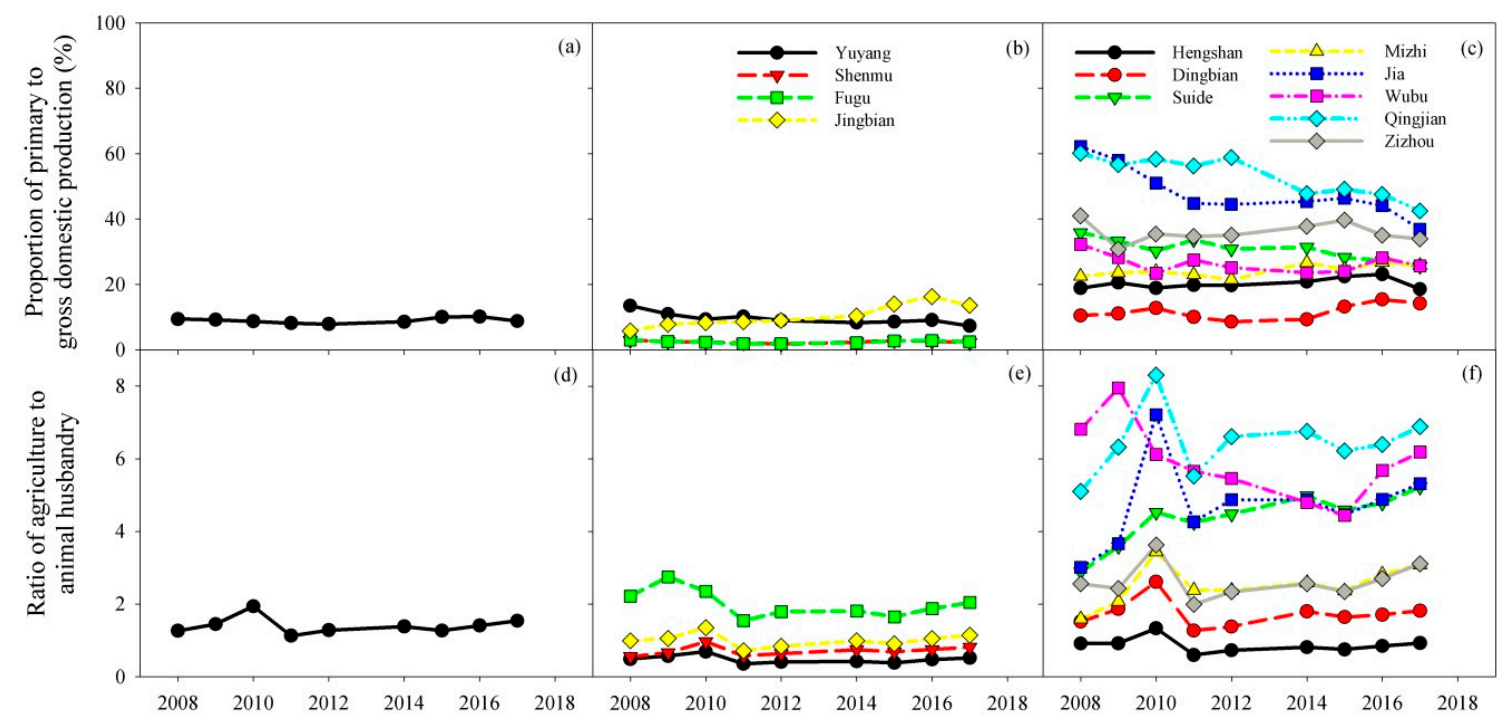

Figure 3. Proportion of primary industry (a-c) and ratio of agriculture to animal husbandry (d-f) in Yulin City $(\mathbf{a}, \mathbf{d})$, non-poverty counties $(\mathbf{b}, \mathbf{e})$ and poverty-stricken counties $(\mathbf{c}, \mathbf{f})$.

\subsubsection{Ratio of Agriculture to Animal Husbandry}

The ratio of agriculture to animal husbandry firstly increased from 1.26 in 2008 to 1.94 in 2010, and then decreased to 1.54 in 2017. Wubu, Suide, Jia, and Qingjian counties had the highest ratio of agriculture to animal husbandry, with values of more than 3 from 2008. The ratio of agriculture to animal husbandry was below 1 in Jingbian, Shenmu, Hengshan, and Yuyang counties, which is lower than the average level of Yulin (Figure 3b).

\subsection{Agricultural Development}

\subsubsection{Agricultural Structural Variability Index}

From 2008 to 2017, agricultural structural variability index in Yulin changed little, ranging from 0.08 to 0.62 . Spatially, relatively significant changes in agricultural structural variability index occurred in Fugu, Shenmu, Jia, and Hengshan counties. Dingbian, Jingbian, Qingjian, Mizhi, and Suide counties displayed no significant changes in agricultural structural variability index (Figure 4a). 


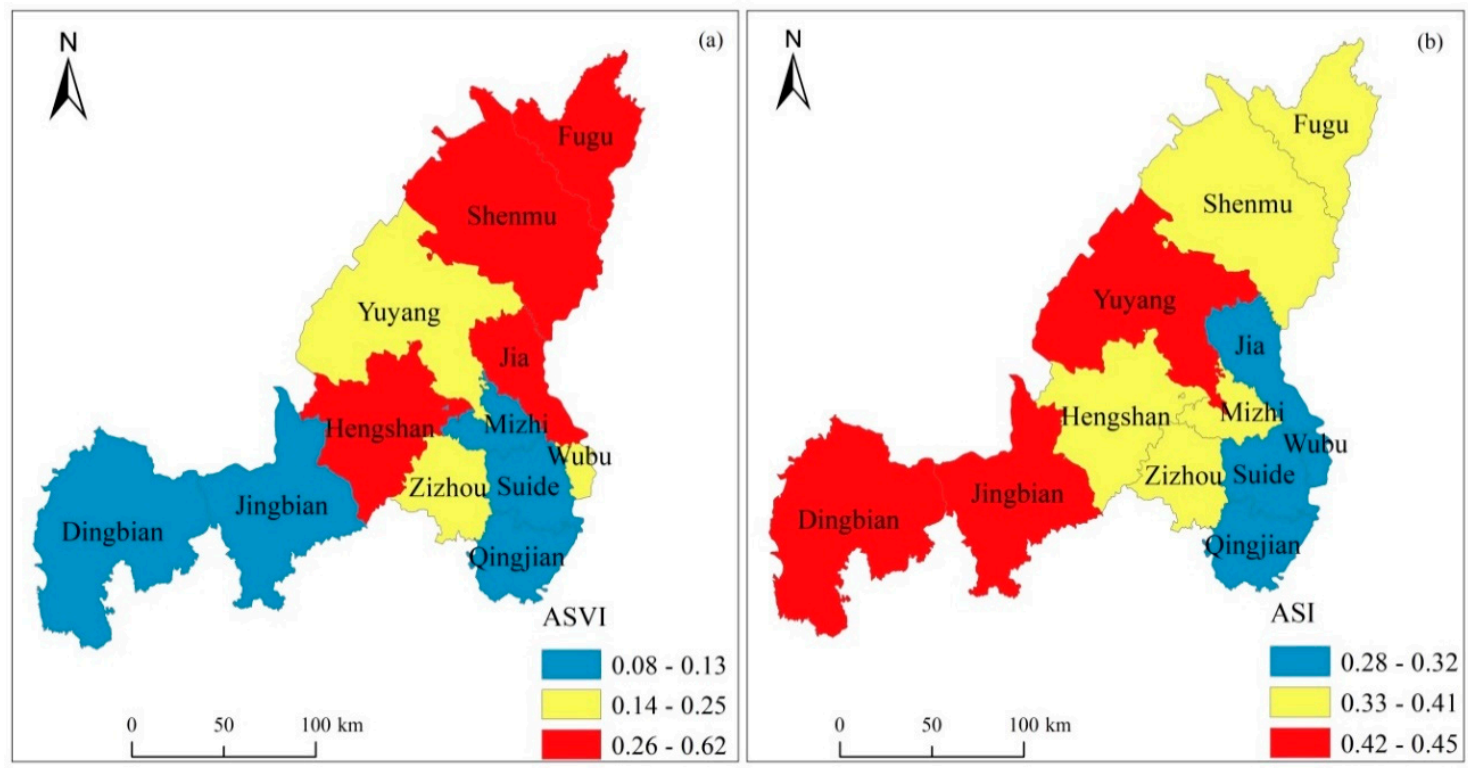

Figure 4. Spatial analysis of the agricultural structure variability index (ASVI) (a) and agricultural specialization index (ASI) (b) in Yulin City during 2008-2017.

\subsubsection{Agricultural Specialization Index}

The agricultural specialization index values in Yulin were all lower than 0.45. Yuyang, Dingbian, and Jingbian had comparably higher agricultural specialization index values than the other counties, while the lowest agricultural specialization index was found in Qingjian, Wubu, Suide, and Jia counties (Figure 4b).

\subsection{Rural Income}

\subsubsection{Rural Per Capita Net Income}

Rural per capita net income in Yulin increased from 3668 yuan in 2008 to 12,999 yuan in 2017. The highest and lowest rural per capita net income were found in Shenmu and Jia, respectively. During 2008-2017, rural per capita net income in Shenmu ranged from 6028 yuan to 17,537 yuan, while it increased from 2731 yuan to 10,514 yuan in Jia. West to northwest counties had higher rural per capita net income values than the average level of Yulin, while the rural per capita net income values in southeast counties were lower than the average level of Yulin (Table 1).

Table 1. Variations in rural per capita net income in Yulin City.

\begin{tabular}{ccccccccccc}
\hline County & $\mathbf{2 0 0 8}$ & $\mathbf{2 0 0 9}$ & $\mathbf{2 0 1 0}$ & $\mathbf{2 0 1 1}$ & $\mathbf{2 0 1 2}$ & $\mathbf{2 0 1 3}$ & $\mathbf{2 0 1 4}$ & $\mathbf{2 0 1 5}$ & $\mathbf{2 0 1 6}$ & $\mathbf{2 0 1 7}$ \\
\hline Yuyang & 4185 & 5321 & 6605 & 8428 & 10,001 & 11,331 & 12,656 & 13,952 & 14,866 & 15,839 \\
Shenmu & 6028 & 7223 & 8672 & 10,798 & 12,537 & 13,225 & 13,622 & 14,740 & 15,569 & 17,537 \\
Fugu & 4703 & 5615 & 7786 & 9927 & 11,783 & 13,001 & 13,409 & 14,490 & 15,229 & 13,025 \\
Hengshan & 3380 & 4215 & 5264 & 6701 & 7860 & 8725 & 9364 & 10,246 & 11,008 & 14,195 \\
Jingbian & 4850 & 6031 & 7599 & 9689 & 11,413 & 12,680 & 13,086 & 14,395 & 15,247 & 16,236 \\
Dingbian & 3411 & 4524 & 6233 & 8010 & 9492 & 10,744 & 11,829 & 13,025 & 13,888 & 14,984 \\
Suide & 2941 & 3686 & 4564 & 5623 & 6630 & 7326 & 8227 & 9018 & 9727 & 10,550 \\
Mizhi & 3368 & 4209 & 5209 & 6407 & 7509 & 8290 & 8903 & 9718 & 10,482 & 11,371 \\
Jia & 2731 & 3435 & 4301 & 5458 & 6408 & 7254 & 8162 & 8941 & 9660 & 10,514 \\
Wubu & 2706 & 3515 & 4403 & 5582 & 6558 & 7352 & 8242 & 8997 & 9723 & 10,576 \\
Qingjian & 2767 & 3502 & 4386 & 5465 & 6500 & 7352 & 8234 & 9011 & 9695 & 10,542 \\
Zizhou & 2946 & 3693 & 4570 & 5621 & 6582 & 7394 & 8296 & 9049 & 9773 & 10,623 \\
Average & 3668 & 4581 & 5799 & 7309 & 8606 & 9556 & 10,336 & 11,299 & 12,072 & 12,999 \\
\hline
\end{tabular}




\subsubsection{Actual Growth Rate of Rural Per Capita Net Income}

Actual growth rate in Yulin continuously declined during 2008-2017. Actual growth rate became negative from 2012, except for Yuyang and Fugu counties. In 2017, AGR became positive in Hengshan County. Fugu County had the most decreased actual growth rate (Figure 5).

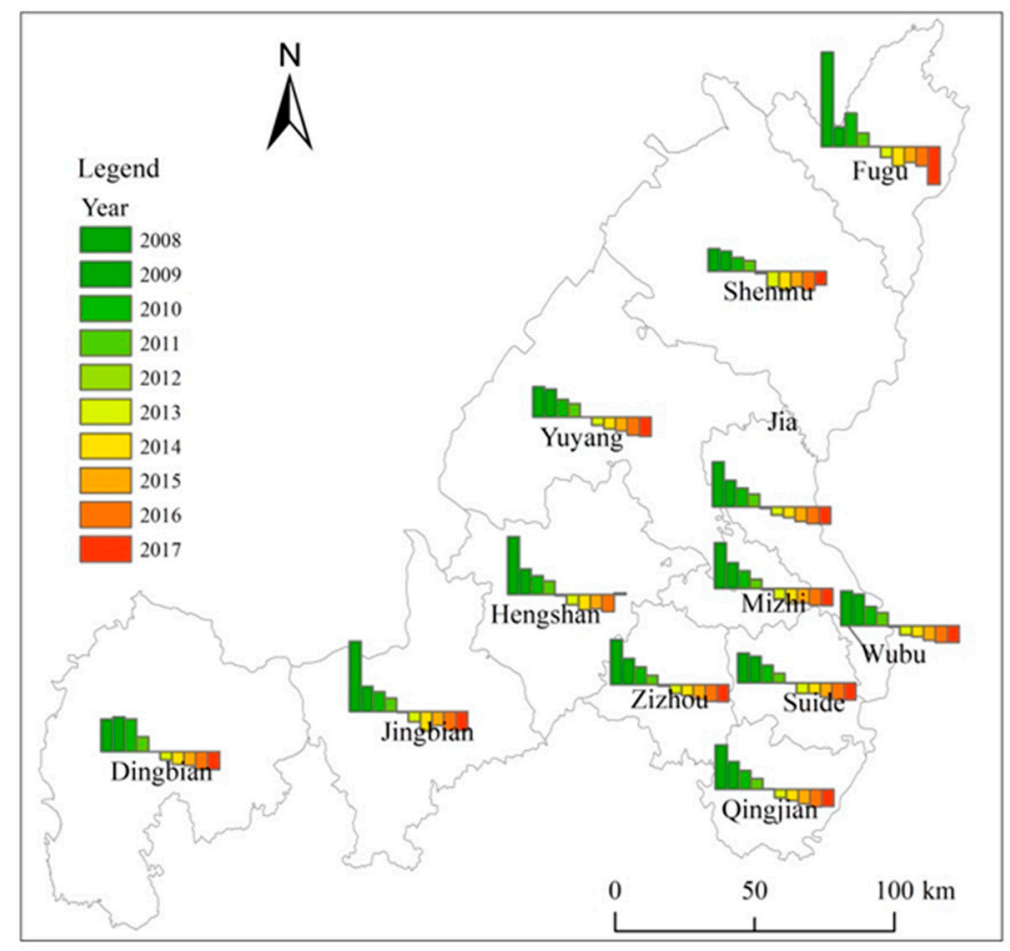

Figure 5. Variations in the actual growth rate in Yulin City during 2008-2017.

\subsection{Relationships Between Rural Poverty and Agricultural Development}

There were significant positive relationships between the rural poverty ratio and proportion of primary industry and ratio of agriculture to animal husbandry (Figure 6a,b, Table 2), while a significantly negative relationship was found between the rural poverty ratio and agricultural specialization index (Figure $6 \mathrm{~d}$, Table 2). There was no significant relationship between the rural poverty ratio and agricultural structural variability index (Figure 6c, Table 2). The proportion of primary industry and ratio of agriculture to animal husbandry were the dominate factors affecting poverty ratio, and could explain $91 \%$ of the variability in the poverty ratio (Table 2 ).

Table 2. Regression models between poverty ratio and agricultural structure indexes.

\begin{tabular}{ccccc}
\hline $\begin{array}{c}\text { Dependent } \\
\text { Variable }\end{array}$ & Independent Variable & Regression Equation & $\mathbf{R}^{2}$ & $p$ Value \\
\hline \multirow{2}{*}{ Poverty ratio } & Proportion of primary industry (PPI) & $\mathrm{Y}=0.4463 \mathrm{PPI}-0.0059$ & 0.83 & $<0.0001$ \\
& Ratio of agriculture to animal husbandry (RAAH) & $\mathrm{Y}=0.0258 \mathrm{RAAH}+0.0063$ & 0.82 & $<0.0001$ \\
& Agricultural specialization index (ASI) & $\mathrm{Y}=-0.6614 \mathrm{ASI}+0.3349$ & 0.46 & 0.0147 \\
\hline & Combined & $\mathrm{Y}=0.252 \mathrm{PPI}+0.014 \mathrm{RAAH}$ & 0.91 & $<0.001$ \\
\hline
\end{tabular}



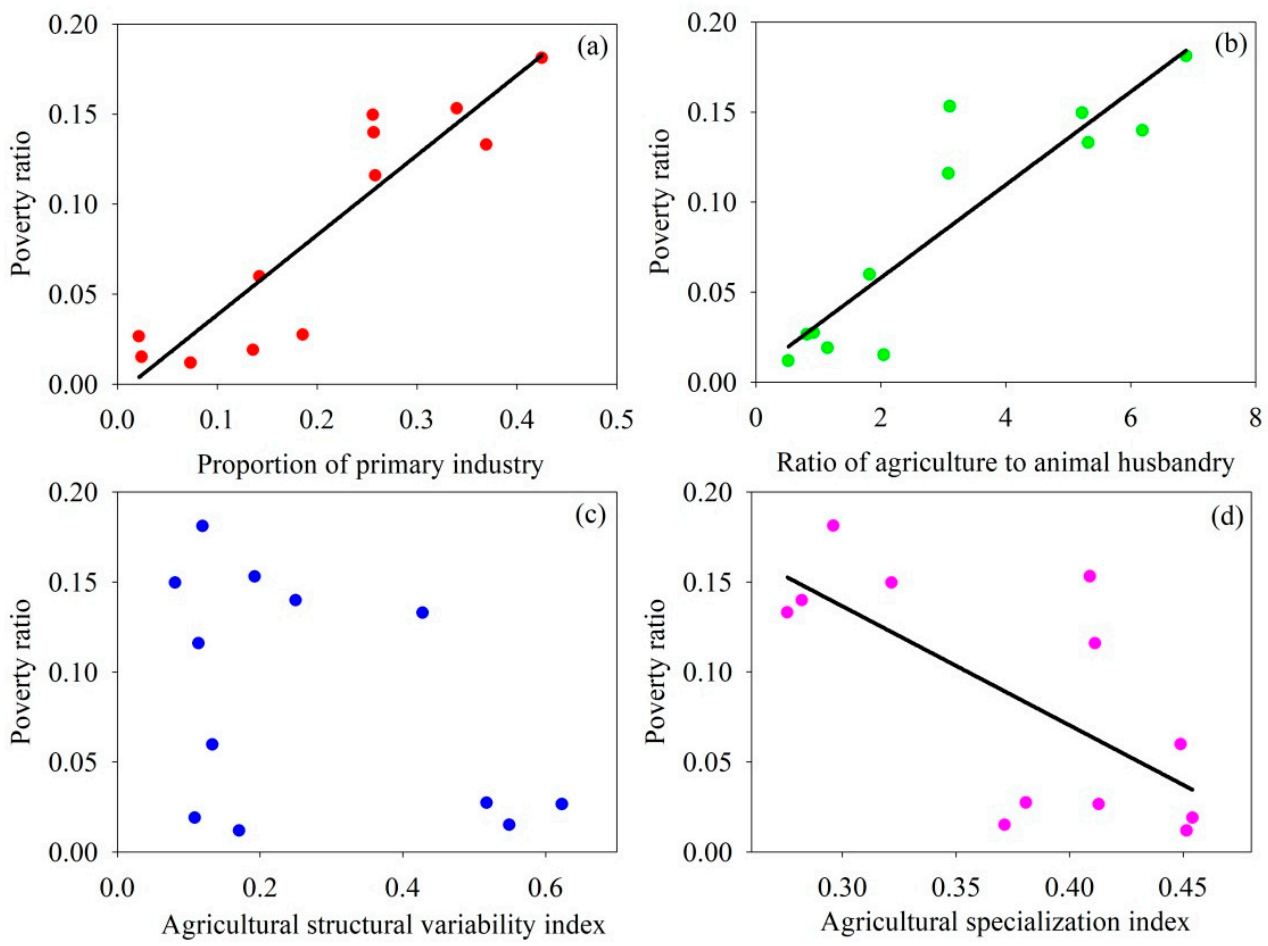

Figure 6. Relationships between rural poverty and proportion of primary industry (a), ratio of agriculture to animal husbandry (b), agricultural structural variability index (c), and agricultural specialization index (d) in Yulin City.

\section{Discussions}

Agricultural structure adjustment and transformation can drive rural development [20]. Understanding the limitation and driving factors of rural economic development is beneficial for increasing the agricultural income and promoting regional poverty reduction [30]. In Yulin, the depression of the energy economy and backward nature of agricultural development have resulted in a significantly negative actual growth rate since 2012 (Figure 5). Higher rural poverty ratio (Figure 2) occurred in southeast counties with a higher proportion of primary industry. Primary industry accounts for more than $30 \%$ of the gross domestic production in six of the eight national-level poverty-stricken counties, including Jia, Qingiian, Zizhou, Suide, Wubu, and Mizhi (Figure 3a). In addition, people living in the agro-pastoral transition zone mainly make their living by agriculture and animal husbandry. Land-based strategies of arable farming and animal husbandry contribute to rural livelihoods in both financial and social terms [31]. Livestock revolution would be an easier way for the poor to improve their income [32]. However, the livestock growth rate was still lower than agriculture development, leading to an increased ratio of agriculture to animal husbandry from 2011, especially due to implementing targeted poverty alleviation in 2014 (Figure 3b). A significant positive relationship between the poverty ratio and proportion of primary industry (Figure 6a) and between the poverty ratio and ratio of agriculture to animal husbandry (Figure $6 \mathrm{~b}$ ) indicated that agricultural transformation is crucial to regional rural poverty alleviation.

Agricultural specialization can reduce the rural labor input [33] and increase agricultural productivity [34]. Integrated land policies and land tenure system reform can lead rural residents to develop moderate-scale and specialized management of farming $[14,26]$. Developing new modes of cooperative land management and production may improve the current rural poverty situation in the agro-pastoral ecotone [35]. Agricultural structural variability index in Yulin has changed little in the past decade (Figure 4a). No significant relationship was found between agricultural structural variability index and rural poverty (Figure 6c), while agricultural specialization index had a significant correlation with rural poverty (Figure $6 \mathrm{~d}$ ). This suggests that agricultural specialization will play an 
important role in eliminating rural poverty in Yulin. Based on the result of stepwise regression analysis (Table 2), we found that a reduced proportion of primary industry and animal husbandry development play significant role in rural poverty reduction. It is noted that the agricultural structural variability index results have a limitation due to the lack of forage data. The Yulin government released a forage grass planting and processing policy in 2014. A "Grain-Economic plant-Fodder-Grass" planting pattern has gradually been established in the northern wind-sand-grass shoal region. Farmlands have been returned to grassland in specific areas of southern loess hilly-gully region. Alfalfa, ryegrass, silage corn, and pacesetter have been introduced [36]. The planting variety and corresponding areas should be studied immediately to support regional agricultural structure adjustment and rural sustainable development.

Agricultural industry development can provide a stable and sustainable income for farmers and realize long-term and hematopoietic poverty reduction [14,37]. In 2013, Yulin was considered to be the second granary of Shaanxi Province due to its abundant groundwater, relatively rich heat energy, improved crop varieties and reclaimable land resources [38]. The government has established an agricultural industrial development plan to promote rural poverty elimination through apples, red dates, coarse cereals, Chinese herbal medicine planting and processing, and livestock breeding (Table 3). A red date industrial district has been constructed along the Yellow River in the Jia, Wubu, and Qingiian counties, with total planting areas of $7.4 \times 10^{4}$ ha. Coarse cereals have mainly been developed in the southern loess hilly-gully regions of Hengshan, Mizhi, and Zizhou counties. In the northern wind-sand-grass shoal region, individual household and scale industry is encouraged to increase the numbers of livestock under the premise of ecological protection. In addition, the extended processing of animal production needs to be highlighted due to the high value-added and additional employment for poor rural areas. In 2017, Hengshan and Dingbian counties became the first batch to successfully escape from rural poverty. Sheep breeding and coarse cereal planting have injected new vitality for increasing households' income and eradicating rural poverty in Hengshan County. Potato planting and processing, as well as facility agriculture development, have mitigated rural poverty through integration with agriculture, industry, and tourism in Dingbian County [26]. In 2018, about 44,000 households participated in characteristic planting and breeding industries. Suide, Mizhi, and Wubu counties have been successfully withdrawn from the list of national-level poverty-stricken counties.

Table 3. Agricultural industry development in Yulin City.

\begin{tabular}{cc}
\hline Agricultural Industry Development & County \\
\hline Red date planting and processing & Jia, Wubu, Qingjian \\
Coarse cereals & Hengshan, Mizhi, Zizhou \\
Potato scale planting and processing & Dingbian, Jingbian \\
Apple & Suide, Jia, Wubu, Qingjian, Hengshan, Mizhi, Zizhou \\
livestock breeding and processing & Hengshan, Yuyang, Shenmu \\
\hline
\end{tabular}

The Chinese government will decrease grain production while encouraging forage development. Therefore, we suggest regional planting, intensive breeding, specialized production, and industrialized operation as the strategies and directions for tackling rural poverty. The agricultural structure can be adjusted from the aspects of proportion of primary industry, ratio of agriculture to animal husbandry, and agricultural specialization index. An extended processing chain will enhance agricultural competitiveness and promote industry amalgamation. Characteristic breeding, brand, and market establishment can improve livestock and husbandry development, and thus decrease the ratio of agriculture to animal husbandry. Specialized organization and professional technical training will support agricultural specialization. Overall, agricultural structure adjustment can provide a guarantee of rural poverty alleviation by increasing the county finances, collective economy, and household incomes (Figure 7). In addition, we also recommended rural poor migration to reduce rural poverty in Yulin. Ex situ relocation is an important measure in China's targeted poverty alleviation strategy. 
Distinctive industries were developed to left the relocated households out of poverty by agricultural scaling planting and industry amalgamation [14]. In Dingbian County, rural industry development was coordinated with the relocation projects to increase the income of relocated poor households. A total of 18,127 poor populations were relocated near tp the agricultural products' gather and distribution parks. All the relocated poor households obtained high-quality farmland and industrial development capital to develop facility agriculture [26].

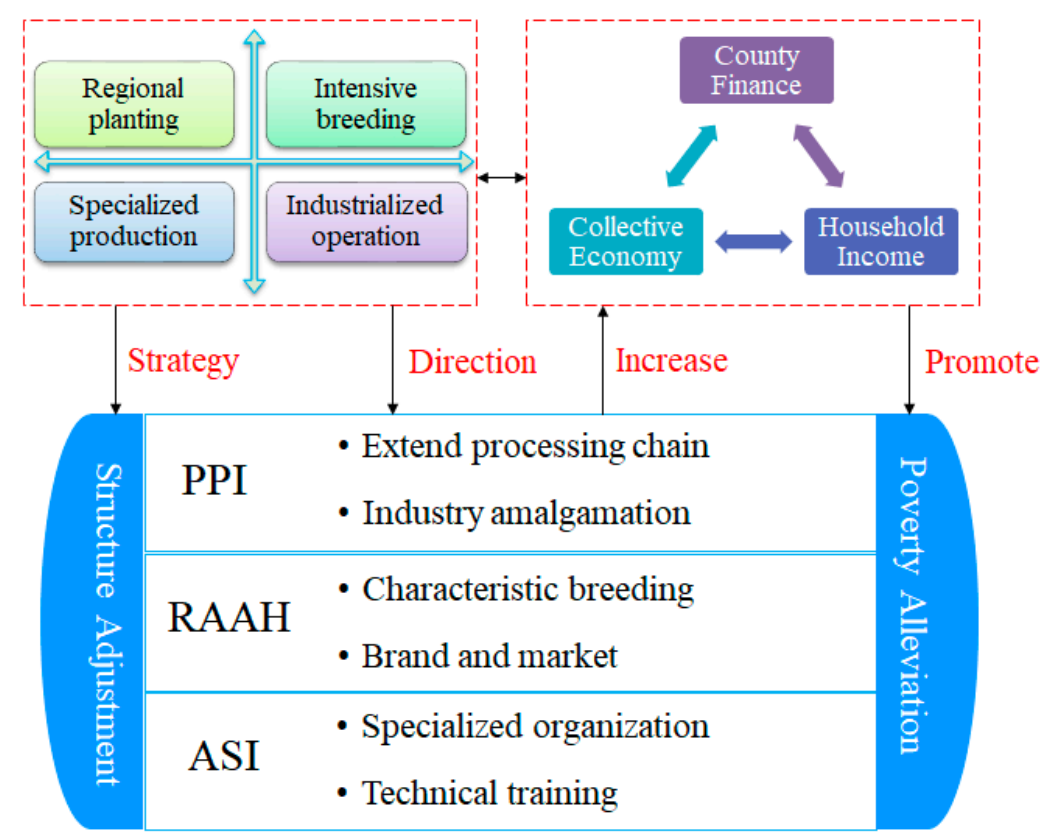

PPI: proportion of primary industry ASI: agricultural structural variability index

RAAH: ratio of agriculture to animal husbandry

Figure 7. Framework of agricultural structure adjustment and rural poverty alleviation in Yulin City.

\section{Conclusions}

Rural decline and attendant poverty are global issues. Agricultural transformation and development play a dominant role in rural poverty alleviation. The agricultural structure's brief retrospect and adjustment strategy is related to rural sustainable development. Yulin is a centralized poverty city with a clear spatial distribution in the southeast region. Southeast counties had a higher proportion of primary to gross domestic production and ratio of agriculture to animal husbandry in this study. Agricultural structural variability index and agricultural specialization index have changed little, while the actual growth rate of rural per capita net income has significantly changed from 2008 to 2017. Positive relationships were found between the rural poverty ratio and the proportion of primary industry, and the ratio of agriculture to animal husbandry; however, a negative relationship was found between the rural poverty ratio and the agricultural specialization index. The linear regression result indicated that proportion of primary industry and ratio of agriculture to animal husbandry were the dominate factors to poverty ratio. Unfortunately, the agricultural structure results are still unconvincing due to the lack of forage data. Further study is necessary to investigate forage planting areas and the agricultural structure adjustment rate.

Author Contributions: Conceptualization, Y.W. and Z.L.; methodology, Y.W. and Y.C.; software, Y.C.; formal analysis, Y.W. and Y.C.; investigation, Y.W. and Y.C.; resources, Y.W.; data curation, Y.C.; writing-original draft preparation: Y.C.; writing - review and editing: Y.W., Z.L. and Y.C.; and project administration. and supervision: Y.W. All authors have read and agreed to the published version of the manuscript.

Funding: This work was supported by the National Natural Science Foundation of China (No. 41801174). 
Conflicts of Interest: The authors declare no conflict of interest.

\section{References}

1. Liu, Y.S. Research on the urban-rural integration and rural revitalization in the new era in China. Acta Geogr. Sin. 2018, 73, 637-650.

2. Long, H.L.; Tu, S.S. Theoretical thinking of rural restructuring. Prog. Geogr. 2018, 37, 581-590.

3. Han, D.; Qiao, J.J.; Ma, Y.L. Spatio-temporal differentiation and evolution of rurality under the background of rapid industrialization:A case study of Gongyi city, Henan province. Geogr. Res. 2017, 36, 2405-2418.

4. Potter, C.; Tilzey, M. Agricultural policy discourses in the European post-Fordist transition: Neoliberalism, neomercantilism and multifunctionality. Prog. Hum. Geogr. 2005, 29, 581-600. [CrossRef]

5. Wilson, G.A. Post-Productivist and multifunctional agriculture. Int. Encycl. Hum. Geogr. 2009, 12, 379-386.

6. Long, H.L.; Liu, Y.S.; Li, X.B.; Chen, Y.F. Building new countryside in China: A geographical perspective. Land Use Policy 2010, 27, 457-470. [CrossRef]

7. Liu, Y.S.; Li, Y.H. Revitalize the world's countryside. Nature 2017, 548, 275-277. [CrossRef]

8. Li, Y.H.; Yan, J.Y.; Wu, W.H.; Liu, Y.S. The process of rural transformation in the world and prospects of sustainable development. Prog. Geogr. 2018, 37, 627-635.

9. Liu, X.P.; Li, Y.H.; Wang, Y.J.; Guo, Z.J.; Zheng, F. Geographical identification of spatial poverty at county scale. Acta Geogr. Sin. 2017, 72, 545-557.

10. Qian, L.Q.; Yu, M.; Lin, W.X. Poverty reduction within the framework of SDGs and Post-2015 Development Agenda. Adv. Clim. Chang. Res. 2015, 6, 67-73.

11. Guo, Y.Z.; Zhou, Y.; Liu, Y.S. Targeted poverty alleviation and its practices in rural China: A case study of Fuping county, Hebei Province. J. Rural Stud. 2019. [CrossRef]

12. Long, H.L.; Zou, J.; Liu, Y.S. Differentiation of rural development driven by industrialization and urbanization in eastern coastal China. Habitat Int. 2009, 33, 454-462. [CrossRef]

13. Liu, Y.S.; Fang, F.; Li, Y.H. Key issues of land use in China and implications for policy making. Land Use Policy 2014, 40, 6-12. [CrossRef]

14. Zhou, Y.; Guo, Y.Z.; Liu, Y.S.; Wu, W.X.; Li, Y.R. Targeted poverty alleviation and land policy innovation: Some practice and policy implications from China. Land Use Policy 2018, 74, 53-65. [CrossRef]

15. Ren, T.T.; Zhou, Z.X. Influence of agricultural structure transformation on ecosystem services and human well-being: Case study in Xi'an metropolitan area. Acta Ecol. Sin. 2018, 39, 2353-2365.

16. Hossain, M. Poverty Alleviation through Agriculture and Rural Development in Bangladesh; Center for Policy Dialogue: Dhaka, Bangladesh, 2003.

17. Gollin, D.; Parente, S.; Rogerson, R. The role of agriculture in development. Am. Econ. Rev. 2002, 92, 160-164. [CrossRef]

18. Irz, X.; Lin, L.; Thirtle, C.; Wiggins, S. Agricultural productivity growth and poverty alleviation. Dev. Policy Rev. 2001, 19, 449-466. [CrossRef]

19. Valdés, A.; Foster, W. Reflections on the role of agriculture in pro-poor growth. World Dev. 2010, 38, 1362-1374. [CrossRef]

20. Li, E.L.; Xu, Y.N.; Yong, Y.J.; Wei, L.X. Agricultural structure adjustment and rural transformation development in China: Taking Gongyi City and Yanling County as examples. Prog. Geogr. 2018, 37, 698-709.

21. Herrendorf, B.; Rogerson, R.; Valentinyi, A. Growth and Structural Transformation. In Research, N.B. o. E. Ed. Available online: https://www.nber.org/papers/w18996.pdf:2013 (accessed on 18 December 2019).

22. Pan, H.F.; Liu, Y.Q.; Wei, G.H. Impact of agricultural industrial structure adjustment on energy conservation and income growth in Western China: A statistical study. Ann. Oper. Res. 2012, 228, 23-33. [CrossRef]

23. Zhen, N.H.; Fu, B.J.; Lü, Y.H.; Zheng, Z.M. Changes of livelihood due to land use shifts: A case study of Yanchang County in the Loess Plateau of China. Land Use Policy 2014, 40, 28-35. [CrossRef]

24. Costantini, V.; Monni, S. Environment, human development and economic growth. Ecol. Econ. 2008, 64, 867-880. [CrossRef]

25. Mink, S.D.; Mundial, B. Poverty, Population, and the Environment; World Bank: Washington, DC, USA, 1993.

26. Wang, Y.S.; Li, Y.H. Promotion of degraded land consolidation to rural poverty alleviation in the agro-pastoral transition zone of northern China. Land Use Policy 2019, 88. [CrossRef] 
27. Liu, Y.S.; Zhang, X.P.; Li, X.W.; Gao, J. Mechanism and regulation of land degradation in Yulin district. J. Geogr. Sci. 2003, 13, 217-224.

28. Li, Y.R.; Cao, Z.; Long, H.L.; Liu, Y.S.; Li, W.J. Dynamic analysis of ecological environment combined with land cover and NDVI changes and implications for sustainable urban-rural development: The case of $\mathrm{Mu}$ Us Sandy Land, China. J. Clean. Prod. 2016, 142, 697-715. [CrossRef]

29. Geng, X.L. Research on the Expansion of Agricultural Science and Technology in Yulin City; Northwest Agriculture and Forestry University: Shaanxi Province, China, 2014.

30. Farris, J.; Larochelle, C.; Alwang, J.; Norton, G.W.; King, C. Poverty analysis using small area estimation: An application to conservation agriculture in Uganda. Agric. Econ. 2017, 48, 671-681. [CrossRef]

31. Shackleton, C.M.; Shackleton, S.E.; Cousins, B. The role of land-based strategies in rural livelihoods: The contribution of arable production, animal husbandry and natural resource harvesting in communal areas in South Africa. Dev. South. Afr. 2001, 18, 581-604. [CrossRef]

32. Delgado, C.; Rosegrant, M.; Steinfeld, H.; Ehui, S.; Courbois, C. Livestock to 2020: The next food revolution. In 2020 Vision Initiative Food, Agriculture, and the Environment Discussion Paper 28; International Food Policy Research Institute: Washington, DC, USA, 1999.

33. Wang, X.; Huang, J.; Rozelle, S. Off-farm employment and agricultural specialization in China. China Econ. Rev. 2016, 42, 155-165. [CrossRef]

34. Kurosaki, T. Specialization and diversification in agricultural transformation: The case of West Punjab, 1903-92. Am. J. Agric. Econ. 2003, 85, 372-386. [CrossRef]

35. Li, D.; Hruska, T.; Talinbayi, S.; Li, W.J. Changing Agro-Pastoral Livelihoods under Collective and Private Land Use in Xinjiang, China. Sustain. Basel 2019, 11, 166. [CrossRef]

36. Xu, W.Z.; Bo, Y.J.; Liu, C.Y.; Zhang, X. Analysis of the Present Situation and Development Countermeasure of Forage Industry in Yulin City of Shaanxi Province. Value Eng. 2017, 14, 222-223.

37. Liu, J.S.; Chen, X.; Cao, J.H. The mechanisms of the industrialization of precise poverty alleviation. China Popul. Resour. Environ. 2017, 27, 127-135.

38. Liu, Y.S.; Zheng, X.Y.; Wang, Y.S.; Cao, Z.; Li, Y.H.; Wu, W.H.; Liu, Z.J.; Liu, H.H.; Li, R. Land consolidation and modern agricultural: A case study from soil particles to agricultural systems. J. Geogr. Sci. 2018, 28, 1864-1874.

(C) 2020 by the authors. Licensee MDPI, Basel, Switzerland. This article is an open access article distributed under the terms and conditions of the Creative Commons Attribution (CC BY) license (http://creativecommons.org/licenses/by/4.0/). 